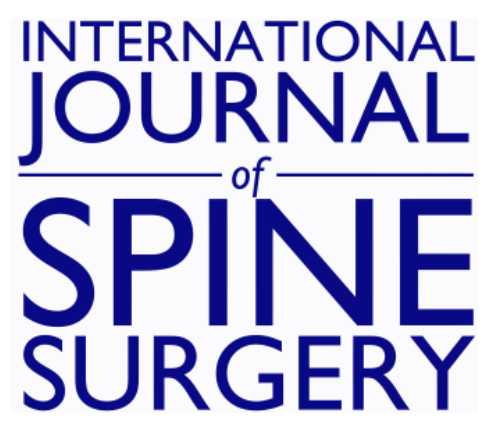

\title{
Fibrous Dysplasia of the Spine--A Case Involving the Polyostotic Form Isolated to the Thoracolumbar Spine
}

Agus Hadian Rahim, Nucki Nursjamsi Hidajat, Ahmad Ramdan and Raden Moechammad Satrio Nugroho Magetsari

Int J Spine Surg 2021, 14 (s4) S46-S51

doi: https://doi.org/10.14444/7164

http://ijssurgery.com/content/14/s4/S46

This information is current as of April 26, 2023.

Email Alerts Receive free email-alerts when new articles cite this article. Sign up at:

http://ijssurgery.com/alerts

The International Journal of Spine Surgery

2397 Waterbury Circle, Suite 1,

Aurora, IL 60504, Phone: +1-630-375-1432 


\title{
Fibrous Dysplasia of the Spine-A Case Involving the Polyostotic Form Isolated to the Thoracolumbar Spine
}

\author{
AGUS HADIAN RAHIM, MD, ${ }^{1}$ NUCKI NURSJAMSI HIDAJAT, MD,${ }^{1}$ AHMAD RAMDAN, MD ${ }^{2}$ \\ RADEN MOECHAMMAD SATRIO NUGROHO MAGETSARI, MD ${ }^{1}$ \\ ${ }^{1}$ Department of Orthopaedics and Traumatology, Faculty of Medicine, Padjadjaran University, Bandung, Indonesia, ${ }^{2}$ Head of Spine Division, Department of \\ Orthopaedics and Traumatology, Faculty of Medicine, Padjadjaran University, Bandung, Indonesia
}

\begin{abstract}
Fibrous dysplasia of the spine in a polyostotic form is very rare, with fewer than 36 cases discussed in the literature and there is no such case in Indonesia that has been reported. The aim of this report is to present a case from Indonesia of polyostotic fibrous dysplasia isolated in the spine. We report a case of a 38-year-old Sundanese man with a 1-year history of progressive back pain and weakness of both lower extremities. There was no history leading to infection and no previous trauma. A physical examination revealed kyphoscoliotic deformity, a café au lait spot, tenderness at the thoracolumbar region, and neurological deficits. Laboratory studies were within normal ranges. Plain radiographs showed lytic lesion and kyphoscoliosis. Magnetic resonance imaging showed an endosteal scalloping, infiltrative process, expansion, and destruction in the vertebral bodies from T2 to L5. The findings of an aggressive destructive process was highly suspicious of a malignant process, relying on differential diagnosis and metastases, plasma cell myeloma, bone tumor and chronic infectious spondylitis. Histology revealed an irregularly oriented osteoid without osteoblastic rimming but surrounded by fibroblastic proliferation with a C-shaped sign. Investigations revealed a diagnosis of polyostotic fibrous dysplasia of the thoracolumbar spine in isolation. The patient underwent T5-S1 stabilization and bone grafting. At 1 year postoperative, the patient was asymptomatic; there was no recurrence and minimal neurological deficit with grade II on the modified McCormick scale. A case of the polyostotic form of fibrous dysplasia of the spine in isolation has never been reported in Indonesia. The extreme rarity of this type of presentation can pose a diagnostic dilemma, and in cases isolated to the spine, surgical treatment with posterior stabilization, decompression, and bone grafting gives a good functional outcome.
\end{abstract}

Tumors

Keywords: fibrous, dysplasia, polyostotic, spine

\section{INTRODUCTION}

Fibrous dysplasia is a benign fibro-osseous lesion of the bone, characterized by the replacement of the medullary component of one (monostotic) or, less commonly, several bones (polyostotic) with fibroblastic tissue. ${ }^{1,2}$ Such tumors are predominantly found in males. Most patients with fibroblastic dysplasia are asymptomatic, but some may present with a pain or swelling on the back. Fibroblastic dysplasia accounts for $7 \%$ of benign bone tumors and $2.5 \%$ of all bone lesions. It may occur in any bone but most commonly in the proximal femur, tibia, ribs, and skull. ${ }^{3}$ Polyostotic disease commonly affects the sphenoid, frontal, maxillary, and ethmoid bones; occipital and temporal bone involvement is rare. ${ }^{4,5}$ The spine is involved in $1.4 \%$ to $5.5 \%$ of fibrous dysplasia lesions. $^{6-8}$ Fibrous dysplasia of the spine in a polyostotic form is very rare, with fewer than 36 cases discussed in the literature, and no such case has previously been reported in Indonesia. The aim of this report is to present a case from Indonesia of polyostotic fibrous dysplasia isolated in the spine.

\section{CASE REPORT}

We report a case of a 38-year-old Sundanese man with a 1-year history of progressive back pain and weakness of both lower extremities. The pain was a stabbing pain, radiating to the trunk and both lower extremities. Initially, the pain was intermittent, then slowly increasing in frequency and severity so that it was interfering with daily life activities. His visual analog scale score was 7 out of 10 . The patient was unable to stand and tended to lie down. There was no history of infection or previous trauma. There was no history of family with the same conditions. A physical examination revealed kyphoscoliotic deformity, a large and irregularly bordered café au lait spot, and tenderness at the thoracolumbar 

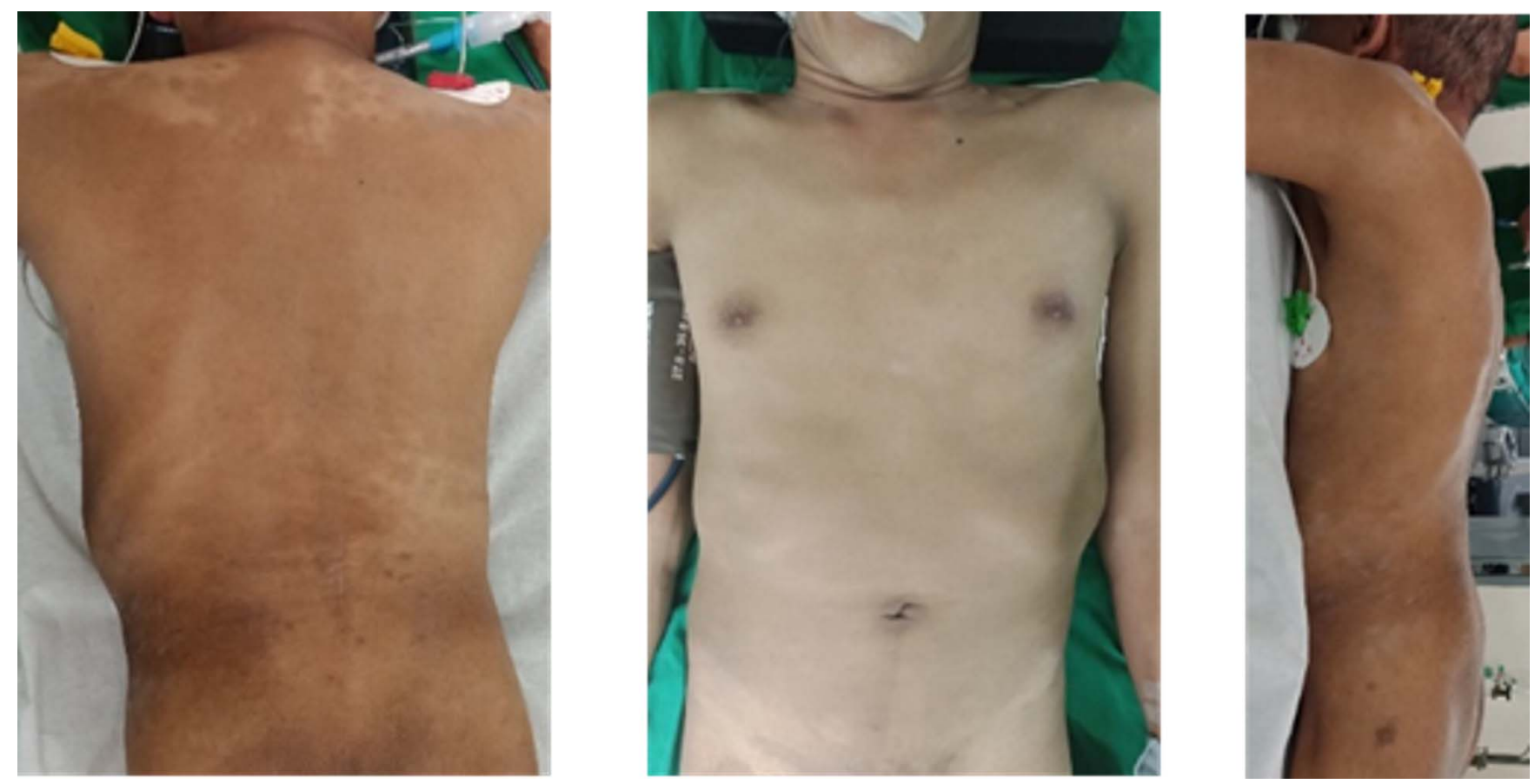

Figure 1. Clinical pictures of a 38-year-old man with kyphoscoliotic deformity and café au lait spot.

region. (Figure 1). His spinal range of motion was limited due to pain. Neurological examination found hypesthesia at levels below the T6 dermatome. Extremity strength examination indicated good strength in all key muscles, except for weakness (4 out of 5) in both lower extremities, especially in dorsiflexion, great toe extension, and plantarflexion. Reflex examination indicated bilateral 3+ hyperreflexia throughout the lower extremities. The Babinski sign was positive in both feet. The straight-leg-raise test was positive at the right leg. He had normal bowel and bladder function.

Laboratory studies were within normal ranges. Plain radiographs showed a lytic lesion and kyphoscoliosis at the thoracolumbar spine. Magnetic resonance imaging of the thoracolumbar area was carried out and the results showed endosteal scalloping, an infiltrative process, expansion, destruction in the multiple vertebral bodies from $\mathrm{T} 2$ to L5 (Figure 2a), and multiple disk bulging with mild cord compression at levels T6-7, T11-12, L1-2, L3-4, and L-L5 (Figure 2b).

The finding of an aggressive destructive process was highly suspicious of a malignant process, relying on differential diagnosis and metastases, plasma cell myeloma, bone tumor, and chronic infectious spondylitis. Histology from core biopsy examination at the lumbar region revealed an
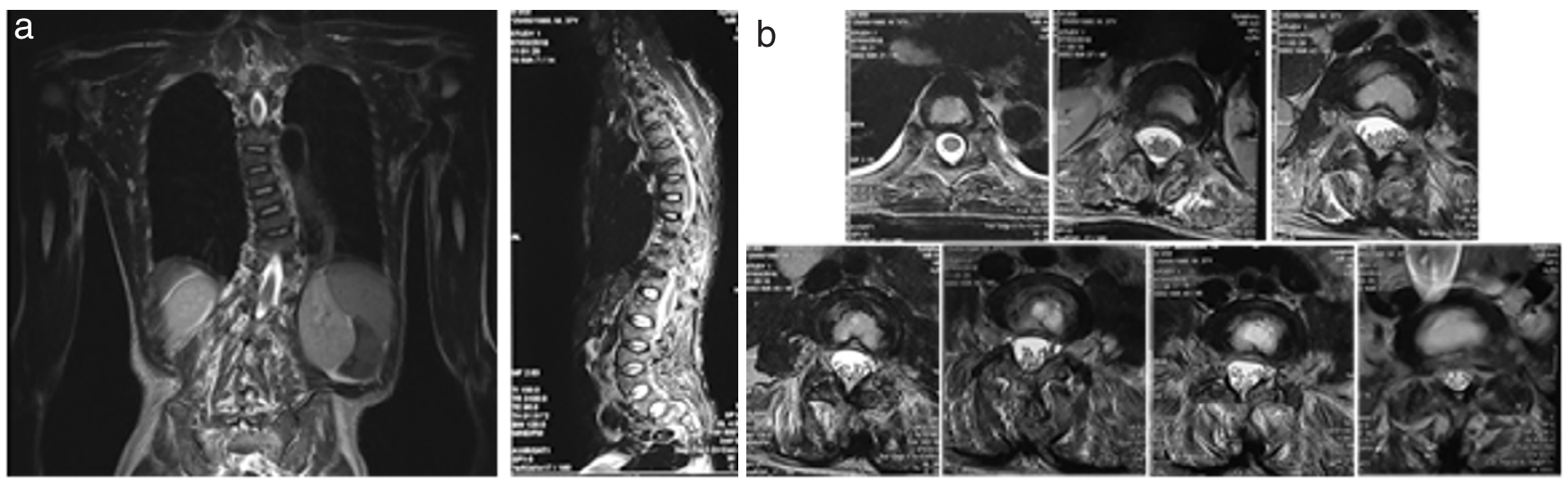

Figure 2. (a) Magnetic resonance imaging of thoracolumbar spine showed endosteal scalloping, infiltrative process, expansion, and destruction in the vertebral bodies from T2 to L5. (b) Multiple disk bulging with mild cord compression at levels T6-7, T11-12, L1-2, L3-4, and L4-5. 

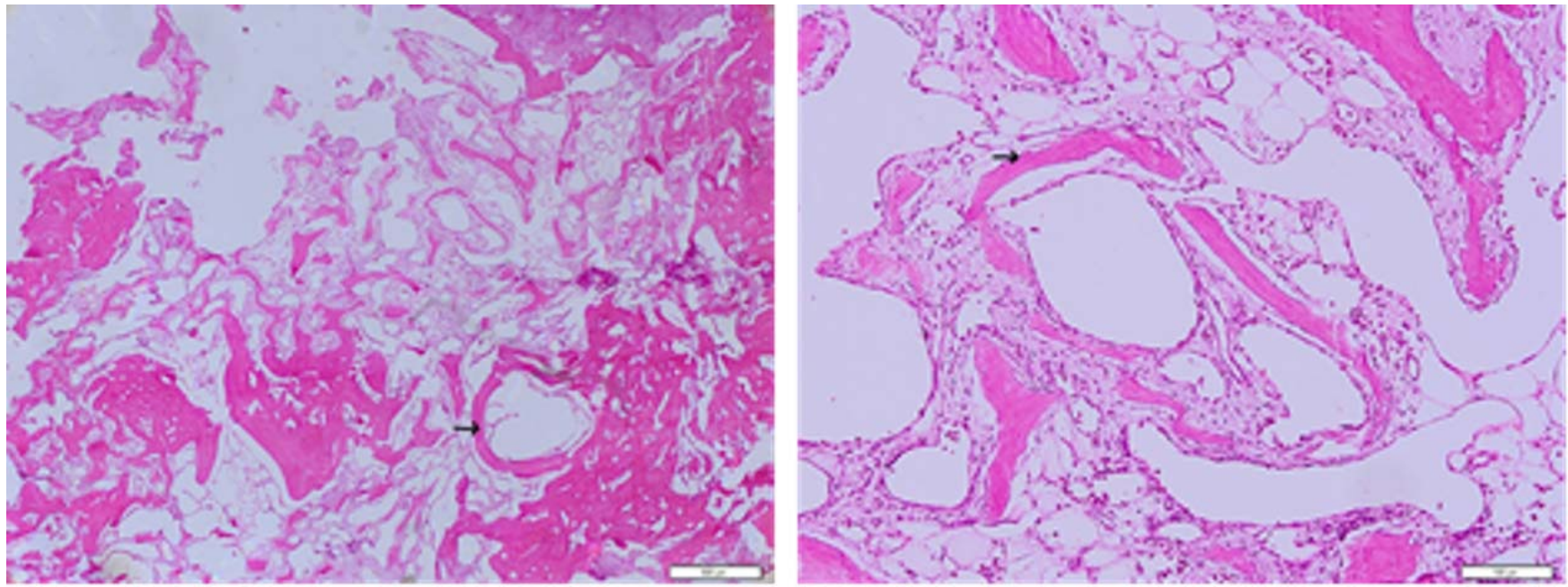

Figure 3. Irregularly oriented osteoid with fibroblastic proliferation and C-shaped sign (black arrow).

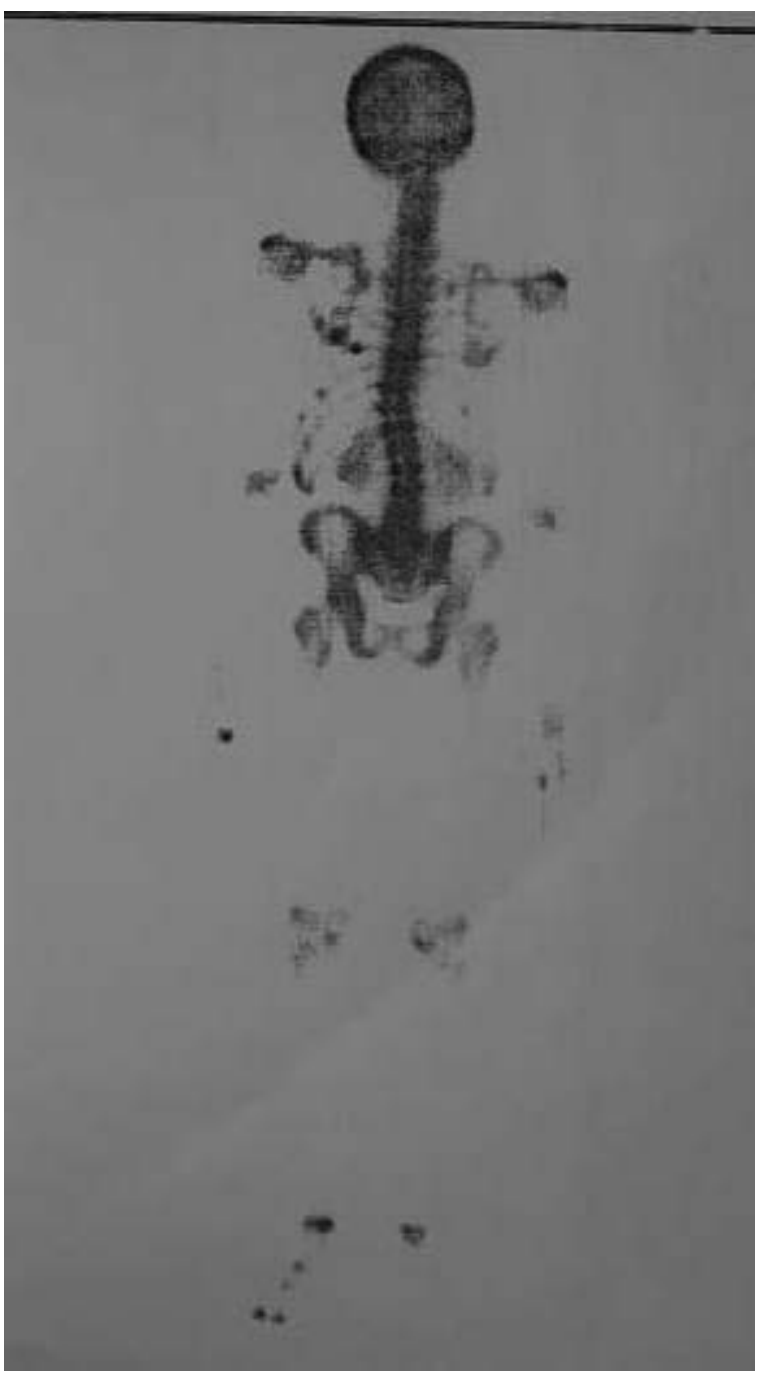

Figure 4. Bone scan revealed isolated hot spot at spine. irregularly oriented osteoid without osteoblastic rimming but surrounded by fibroblastic proliferation with $\mathrm{C}$-shaped sign (Figure 3). A bone scan investigation revealed an isolated hot spot at the spine. Investigations revealed a diagnosis of polyostotic fibrous dysplasia isolated to the thoracolumbar spine (Figure 4). The patient underwent decompression with partial laminectomy, pedicle screw fixation, and fusion with bone grafting. Partial laminectomy was performed at levels T6-7, T11-12, L1-2, L2-3, L4-5, and L5-S1 under general anesthesia (Figure 5). Pedicle screws were inserted with biplanar fluoroscopy guidance (left T5, T7, T9,

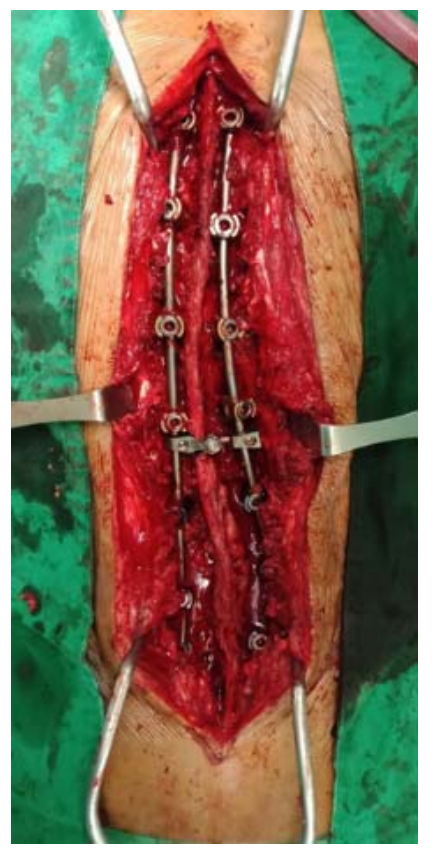

Figure 5. The patient treated with T5-S1 posterior stabilization and bone grafting. 

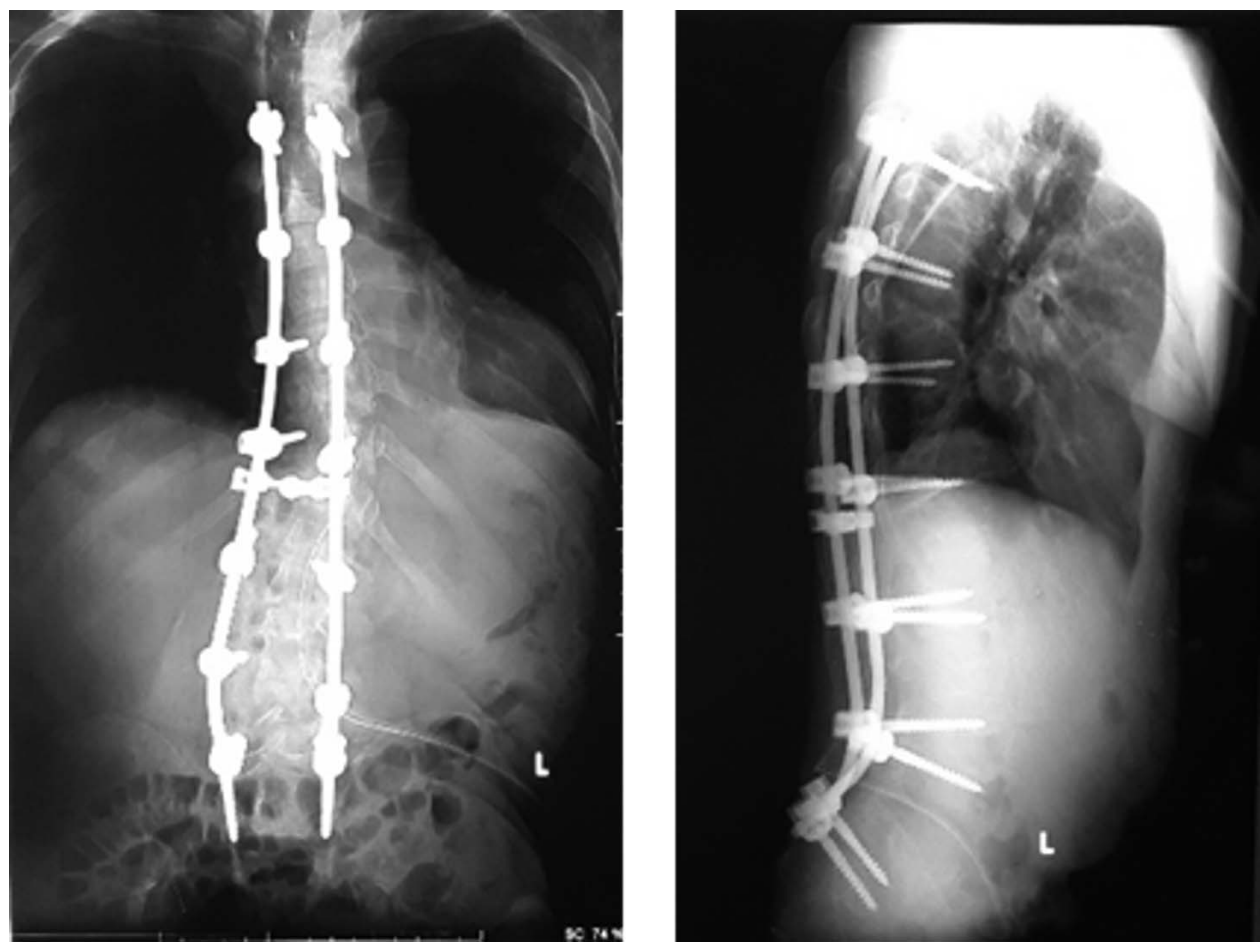

Figure 6. Anteroposterior and lateral radiographs showing the final result after decompression and pedicle screw fixation from T5 to S1.

T11, L1, L3, L4, and S1 pedicles; right T5, T7, T9, T11, L1, L3, L5, and S1 pedicles). The operative time was 210 minutes, and the estimated blood loss was $2000 \mathrm{~mL}$. Two weeks after the operation, the visual analog scale was 3 . The pathologic diagnosis of fibrous dysplasia was confirmed by histologic examination. Risedronate sodium was administered orally, $35 \mathrm{mg}$ once a week, in combination with vitamin $\mathrm{D}$ and calcium. The patient had recovered from neurologic deficit and back pain at the 3month follow-up. Atr 1 year postoperative, the patient was asymptomatic, with no recurrence and

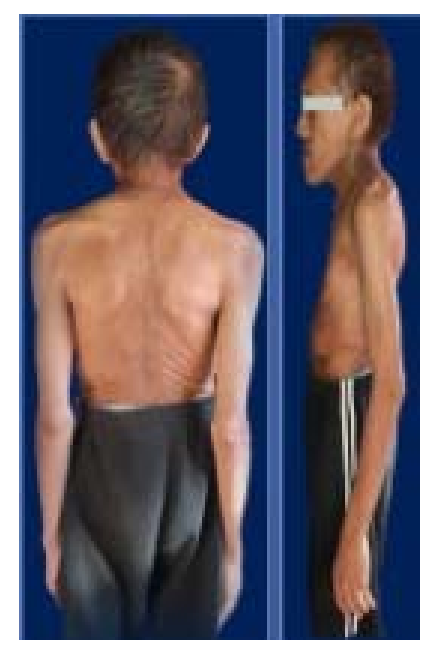

Figure 7. Clinical pictures after 1 year postoperative. minimal neurological deficit with grade II on the modified McCormick scale (Figures 6 and 7).

\section{DISCUSSION}

Fibrous dysplasia was first described by Von Recklinghausen in $1891 .{ }^{9}$ It is a slow, progressive bone disorder characterized by replacement of normal cancellous bone in the medullary canal with immature fibro-osseous tissue. ${ }^{10-12}$ According to the involvement of the bones, it is classified into 2 forms: monostotic and polyostotic. The polyostotic form is rarer than the monostotic variant. ${ }^{13}$ The prevalence of spinal involvement is very low, also the presence of multiple lesions of fibrous dysplasia in the thoracolumbar spine in isolation is rare. ${ }^{3} \mathrm{In}$ the previous study conducted by Leet et al, ${ }^{14}$ none of the cases from a large cohort of patients had isolated spinal localization. The clinical features of fibrous dysplasia are usually painless and asymptomatic; when symptoms occur they usually manifest as pain, swelling, and deformity. In our case, the patient had a progressive back pain with weakness in both lower extremities and kyphoscoliotic deformity in thoracolumbar region. ${ }^{15-18}$

On plain radiographs, it appears as a lytic lesion in the metaphysis or diaphysis with a "ground glass" appearance. In our case, the plain radiographs showed lytic lesions along with kyphoscoliotic 
deformity. Magnetic resonance imaging was done to evaluate the soft tissue component and the extent of a lesion. In our case, the results showed endosteal scalloping, infiltrative process, expansion, and destruction in the vertebral bodies from T2 to L5. However, fibrous dysplasia cannot be diagnosed only through radiographic findings. Histopathological examination is needed to rule out the differential diagnoses, which include metastases, plasma cell myeloma, bone tumors, and chronic infectious spondylitis. The lesion may also be complicated by fractures and reparative changes. Hemangioma, giant cell tumor, and aneurysmal bone cyst are also some of the cases of fibrous dysplasia with lytic lesions. Histology revealed an irregularly oriented osteoid without osteoblastic rimming but surrounded by fibroblastic proliferation with a $\mathrm{C}$-shaped sign which corresponded to the previous case reported by Joyce et al. ${ }^{19}$

The treatment of fibrous dysplasia was determined by the presence of the symptoms. In the present case, the spinal cord was compressed and stretched by the kyphoscoliotic deformity. Surgery is indicated for a patient with persistent pain, neurologic impairment, vertebral collapse, instability, and/or cord compression. ${ }^{20}$ We performed a surgical treatment regarding this condition in order to achieve following goals: decompression of the spinal cord, maintenance of spinal stability, eradication of symptomatic lesions, and prevention of further pathological fractures. In our case, the patient underwent a surgical treatment by performing T5-S1 stabilization, decompression, and fusion with bone grafting. One year after the surgery, the patient was asymptomatic, showed no sign of recurrence and minimal neurological deficit with a grade II on the modified McCormick scale.

\section{CONCLUSION}

A case of the polyostotic form of fibrous dysplasia isolated to the spine has never been previously reported in Indonesia. The extreme rarity of this type of presentation can pose a diagnostic dilemma, and in cases that are isolated to the spine, surgical treatment with posterior stabilization, decompression, and bone grafting gives a good functional outcome.

\section{REFERENCES}

1. Firat D, Stutzman L. Review of twenty-four cases: fibrous dysplasia of the bone. Am J Med. 1968;44(3):421-429.
2. Gibson MJ, Middlemiss JH. Fibrous dysplasia of bone. $\mathrm{Br}$ J Radiol. 1971;44(517):1-13.

3. Gogia N, Marwaha V, Atri S, Gulati M, Gupta R., Fibrous dysplasia localized to spine: a diagnostic dilemma. Skeletal Radiol. 2007;36(1):19-23.

4. Lambert PR, Brackmann DE. Fibrous dysplasia of the temporal bone: the use of computerized tomography. Otolaryngol Head Neck Surg. 1984;92:461-467.

5. Song JJ, Jung HH, Lee HM, et al. Monostotic fi brous dysplasia of temporal bone: report of two cases and review of its characteristics. Acta Otolaryngol. 2005;125:1126-1129.

6. Saglik Y, Atalar H, Yildiz Y, et al. Management of fibrous dysplasia. A report on 36 cases. Acta Orthop Belg. 2007;73:96-101.

7. Ippolito E, Bray EW, Corsi A, et al. Natural history and treatment of fibrous dysplasia of bone: a multicenter clinicopathologic study promoted by the European Pediatric Orthopaedic Society. J Pediatr Orthop B. 2003;12:155-177.

8. Dahlin DC, Unni KK. Conditions that commonly simulate primary neoplasms of bone. In: Dahlin DC, Unni KK, eds. Bone Tumors: General Aspects and Cata on 8,542 Cases. 4th ed. Springfield, IL: Charles C Thomas; 1986:413420.

9. Von Recklinghausen. Die fibrose oder deformierende Ostitis, die Osteomalacie und die osteoplastische Carcinose in ihren gegenseitigen Beziehungen. In: Festschrift Rudolf Virchow zum 13. Berlin, Germany: Georg Reimer Verlag; 1891.

10. Weinstein LS, Shenker A, Gejman PV, et al. Activating mutations of the stimulatory $\mathrm{G}$ protein in the McCune-Albright syndrome. N Engl J Med. 1991;325:1688-1695.

11. Schwindinger WF, Francomano CA, Levine MA. Identification of a mutation in the gene encoding the alpha subunit of the stimulatory $G$ protein of adenylyl cyclase in McCune-Albright syndrome. Proc Natl Acad Sci U S A. 1992;89:5152-5156.

12. Shenker A, Weinstein LS, Sweet DE, et al. An activating Gs alpha mutation is present in fibrous dysplasia of bone in the McCune-Albright syndrome. $J$ Clin Endocrinol Metab. 1994;79:750-755.

13. Singer J, Sundaram M, Merenda G, et al. Fibrous dysplasia of thoracic vertebra arising de novo: cheirurgogenic in origin? Orthopedics. 1991;14:355-358.

14. Leet AI, Magur E, Lee JS, et al. Fibrous dysplasia in the spine: prevalence of lesions and association with scoliosis. $J$ Bone Joint Surg. 2004;86(3):531-537.

15. Rosenblum B, Overby C, Levine M, et al. Monostotic fibrous dysplasia of the thoracic spine. Spine. 1987;12:939-942.

16. Arazi M, Guney O, Ozdemir M, et al. Monostotic fibrous dysplasia of the thoracic spine: clinicopathological description and follow up. Case report. J Neurosurg Spine. 2004;100:3-6.

17. Parekh SG, Donthineni-Rao R, Ricchetti E, et al. Fibrous dysplasia. J Am Acad Orthop Surg. 2004;12:305-313.

18. Ippolito E, Bray EW, Corsi A, et al. Natural history and treatment of fibrous dysplasia of bone: a multicenter clinicopathologic study promoted by the European Pediatric Orthopaedic Society. J Pediatr Orthop B. 2003;12:155-177.

19. Joyce KM, O'hEireamhoin S, Tan Chien Sheng M, Devitt A. Fibrous dysplasia of the spine - a case involving three levels of thoracic spine. J Orthop Case Rep. 2014;4(2):73-77.

20. Stanton RP, Ippolito E, Springfield D, et al. The surgical 
management of fibrous dysplasia of bone. Orphanet $J$ Rare Dis. 2012;7(suppl 1):S1.

Disclosures and COI: The authors had no sources of funding.

Corresponding Author: R.M.S.N Magetsari, MD, Department of Orthopaedics and Traumatology, Faculty of Medicine, Padjadjaran University, Jl. Pasteur, No. 38, 40161 Bandung, Indonesia.
Phone: +62 8112251 307; Email: satrio.magetsari@ gmail.com.

Published 11 February 2021

This manuscript is generously published free of charge by ISASS, the International Society for the Advancement of Spine Surgery. Copyright (C) 2020 ISASS. To see more or order reprints or permissions, see http://ijssurgery.com. 